\title{
Nationwide trends in chemotherapy use and survival of elderly patients with metastatic pancreatic cancer
}

\author{
Lydia G. M. van der Geest ${ }^{1}$ (D), Nadia Haj Mohammad², Marc G. H. Besselink ${ }^{3}$ \\ Valery E. P. P. Lemmens ${ }^{1,4}$, Johanneke E. A. Portielje 5,6 , Hanneke W. M. van Laarhoven ${ }^{7}$ \& \\ J. (Hanneke) W. Wilmink ${ }^{7}$ for the Dutch Pancreatic Cancer Group \\ 1Department of Research, Netherlands Comprehensive Cancer Organisation (IKNL), Utrecht, The Netherlands \\ ${ }^{2}$ Department of Medical Oncology, University Medical Center Utrecht, Utrecht, The Netherlands \\ ${ }^{3}$ Department of Surgery, Academic Medical Center, Amsterdam, The Netherlands \\ ${ }^{4}$ Department of Public Health, Erasmus Medical Center, Rotterdam, The Netherlands \\ ${ }^{5}$ Department of Internal Medicine and Medical Oncology, Haga Hospital, The Hague, The Netherlands \\ ${ }^{6}$ Foundation of Geriatric Oncology Netherlands (GeriOnNe), Eindhoven, The Netherlands \\ ${ }^{7}$ Department of Medical Oncology, Academic Medical Center, Amsterdam, The Netherlands
}

\section{Keywords}

Chemotherapy, distant metastasis, elderly, pancreatic adenocarcinoma, survival

\section{Correspondence}

L.G.M. van der Geest, Netherlands

Comprehensive Cancer Organisation (IKNL), Godebaldkwartier 419, 3511 DT Utrecht, The Netherlands.

Tel: +31882346479;

E-mail: L.vanderGeest@iknl.nl

Funding Information

No funding information provided.

Received: 12 May 2017; Revised: 22 August 2017; Accepted: 25 September 2017

Cancer Medicine 2017; 6(12):2840-2849

doi: $10.1002 / c a m 4.1240$

\begin{abstract}
Despite an aging population and underrepresentation of elderly patients in clinical trials, studies on elderly patients with metastatic pancreatic cancer are scarce. This study investigated the use of chemotherapy and survival in elderly patients with metastatic pancreatic cancer. From the Netherlands Cancer Registry, all 9407 patients diagnosed with primary metastatic pancreatic adenocarcinoma in 2005-2013 were selected to investigate chemotherapy use and overall survival (OS), using Kaplan-Meier and Cox proportional hazard regression analyses. Over time, chemotherapy use increased in all age groups $(<70$ years: from 26 to $43 \%, 70-74$ years: 14 to $25 \%, 75-79$ years: 5 to $13 \%$, all $P<0.001$, and $\geq 80$ years: 2 to $3 \% P=0.56$ ). Median age of 2,180 patients who received chemotherapy was 63 years (range $21-86$ years, $1.6 \%$ was $\geq 80$ years). In chemotherapy-treated patients, with rising age $(<70,70-74,75-79, \geq 80$ years), microscopic tumor verification occurred less frequently (91-88-87-77\%, respectively, $P=0.009$ ) and OS diminished (median 25-26-19-16 weeks, $P=0.003$ ). After adjustment for confounding factors, worse survival of treated patients $\geq 75$ years persisted. Despite limited chemotherapy use in elderly age, suggestive of strong selection, elderly patients ( $\geq 75$ years) who received chemotherapy for metastatic pancreatic cancer exhibited a worse survival compared to younger patients receiving chemotherapy.
\end{abstract}

\section{Introduction}

Pancreatic cancer is one of the most dismal types of cancer, with a 5 -year survival rate of only $5-7 \%[1,2]$. These low survival rates reflect an advanced stage at diagnosis in the vast majority of patients: at least half of patients already have metastatic disease at time of diagnosis [3, 4]. Median survival of unselected patients with metastatic disease is only 2-3 months [3-5].

Pancreatic cancer is predominantly a disease of the elderly $[2,6]$, at least half of all patients are over 70 years of age and more than one-fifth is older than 80 years $[6,7]$. Unfortunately, elderly patients are underrepresented in clinical trials. For example, the phase III study which showed that FOLFIRINOX (oxaliplatin, irinotecan, fluorouracil, and leucovorin) significantly improved survival compared with gemcitabine monotherapy (median survival 11.1 vs. 6.8 months, respectively) excluded patients over 75 years of age [8]. The phase III study on the combination of gemcitabine and nab-paclitaxel included patients until 88 years of age (median survival 8.5 months vs. 6.7 months in patients with gemcitabine-alone), but the 
median age of 63 years suggests that few patients were older than 75 years [9].

Population-based studies have shown that in the past decades the administration of palliative chemotherapy steeply increased in patients with metastatic pancreatic cancer $[3,10]$. Whether the increased use of chemotherapy also applies to elderly patients, is unknown. Furthermore, some specialized institutions have reported acceptable safety and efficacy of chemotherapy in selected elderly patients with metastatic pancreatic cancer, with survival comparable with younger patients [11-13]. However, in these reports a direct comparison with younger patients $(<75$ years) was not performed $[11,12]$ or a single age cut-off $(<70$, $\geq 70$ years) was used [13] which may mask variation within the older age group. To the best of our knowledge, no population-based studies have been published which compare survival after chemotherapy according to age.

Therefore, the purpose of this nationwide study is to examine the use of chemotherapy and its impact on overall survival in elderly patients with metastatic pancreatic cancer, using multiple age groups.

\section{Methods}

\section{Netherlands cancer registry}

In the Netherlands, a country with approximately 16.8 million inhabitants, all newly diagnosed malignancies are recorded in the nationwide Netherlands Cancer Registry (NCR). Besides notification by the automated pathological archive (PALGA), the National Registry of Hospital Discharge Diagnoses is used. Subsequently, trained registrars collect information on patient, tumor and primary treatment from the medical records in all Dutch hospitals. The International Classification of Diseases for Oncology (ICD-O-3) is used for coding of morphology and tumor locations [14]. Histologically confirmed malignancies are staged according to the Tumor-Node-Metastasis (TNM) staging classification [15]. In patients without microscopically verified diagnosis a summary stage is recorded (Extent of Disease, EoD). Data quality is high and completeness is estimated to be at least 95\%. Follow-up for all patients is obtained by routinely linking the NCR to the Municipal Personal Records Database (BRP). The BRP contains information on the vital status of all Dutch inhabitants (dead or alive, date of death or emigration). The NCR Review Board approved the study.

\section{Patients}

For this study, from the NCR all patients were selected who were diagnosed with primary invasive pancreatic (ductal) adenocarcinoma in the period 2005-2013
(ICD-O-3 C25, morphology codes 8010, 8012, 8020, 8140, $8141,8260,8310,8440,8470,8480,8481,8490,8500$, 8560 , or a nonmicroscopic verified invasive neoplasm of the pancreas suspected for adenocarcinoma). Patients diagnosed at autopsy, younger than 18 years or residing abroad were excluded. TNM and EoD staging information were combined to select patients with metastatic disease at diagnosis ( $53 \%$ of patients).

To investigate a possible age gradient or age cut-off point, patients were divided into four age groups: $<70$ years, $70-74$ years, $75-79$ years and $\geq 80$ years of age. Due to the nature of the NCR, information on prior primary malignancies was available in all patients. Additionally, a slightly modified version of the Charlson classification was recorded region-wide within 1-2 out of nine cancer regions ( $18 \%$ of all patients). Serious comorbid conditions included chronic obstructive pulmonary diseases, cardiovascular diseases, cerebrovascular diseases, digestive tract diseases, diabetes mellitus and other serious diseases. The number of comorbidities were categorized in three groups $(0,1$, $\geq 2$ ). Furthermore, data on socioeconomic status (SES) were used [16]. SES was based on reference data from The Netherlands Institute for Social Research. Scores on social deprivation were derived from income, education and occupation per 4-digit postal code, and were broken into three SES-categories (high: 1st-3rd, intermediate: 4th-7th, low: 8th-10th deciles). Registered treatment after diagnosis included the cancer treatment modalities as mentioned in the treatment plan and provided to the patient (i.c. resection, radiotherapy, chemotherapy). Time intervals between date of diagnosis and date of initiating chemotherapy were calculated to explore possible delay.

Survival time was calculated from the date of diagnosis to the date of death or 1 January 2015, whichever came first. To reduce the influence of survivor treatment selection bias in analysis of survival of patients with versus without chemotherapy [17], only patients were selected who survived at least 30-days after diagnosis (conditional survival). In addition to information about delay of starting chemotherapy, survival time from the starting date of chemotherapy was calculated.

\section{Statistical analysis}

In each age group of patients with metastatic pancreatic cancer, Chi square tests for trend were performed to assess the administration of chemotherapy in consecutive 3-year periods (2005-2007, 2008-2010, 2011-2013). A two-sided $P<0.05$ was considered statistically significant. In patients receiving palliative chemotherapy, Chi-square tests were also used to compare patient, tumor and treatment characteristics between age groups. To compare time intervals between groups of patients, nonparametric 
Kruskal-Wallis tests were used. Univariable and multivariable logistic regression analyses were performed to investigate the association of patient and tumor characteristics with the administration of chemotherapy. Kaplan-Meier analyses with log rank tests were used (1) to evaluate overall survival of all patients with metastatic disease and (2) to compare overall and conditional survival of chemotherapy-treated and untreated patients within the different age groups. In patients receiving chemotherapy, univariable and multivariable Cox proportional hazard regression analyses were performed to evaluate predictors for a worse survival, using survival time calculated from (1) date of diagnosis and from (2) starting chemotherapy. In multivariable models, a backward stepwise elimination procedure was used with a $P>0.10$ in likelihood ratio tests for removal of variables. Missing values were included as separate categories or dummy variables. In sensitivity analyses using regionwide data only, the additional influence of the number and type of comorbid conditions was investigated (in addition to the predictors derived from the multivariable models in the total population). All analyses were performed using STATA/SE (version 13.0; STATA Corp., College Station, TX).

\section{Results}

\section{Patients with metastatic pancreatic cancer}

Of 9,407 patients diagnosed with metastatic pancreatic cancer in the period 2005-2013,32\% was 75 years or older. Twenty-three per cent of all patients received palliative chemotherapy. Over time, the administration of palliative chemotherapy more than doubled from $13 \%$ in 2005 to $30 \%$ in $2013(P<0.001)$. Although treatment with chemotherapy was far less common in elderly patients, an increased use of chemotherapy was found in all age groups (Fig. 1). In consecutive 3-year periods, from 26\% to $43 \%$ of patients under age 70 years received chemotherapy, from $14 \%$ to $25 \%$ of patients aged $70-74$ years and from $5 \%$ to $13 \%$ of patients aged $75-79$ years (all $P<0.001$ ). Over age 80 years very few patients were treated with chemotherapy and the very small increase of $2-3 \%$ was not statistically significant $(P=0.56)$. Besides elderly patients ( $\geq 70$ years) and patients diagnosed in earlier years, also patients living in low SES neighborhoods, without tumor verification, with tumors located in the pancreatic head and patients with multiple metastatic sites independently had a lower probability of receiving chemotherapy (Table 1), In addition, the accumulation of comorbid conditions showed a stronger association with not receiving chemotherapy than specific comorbid conditions.

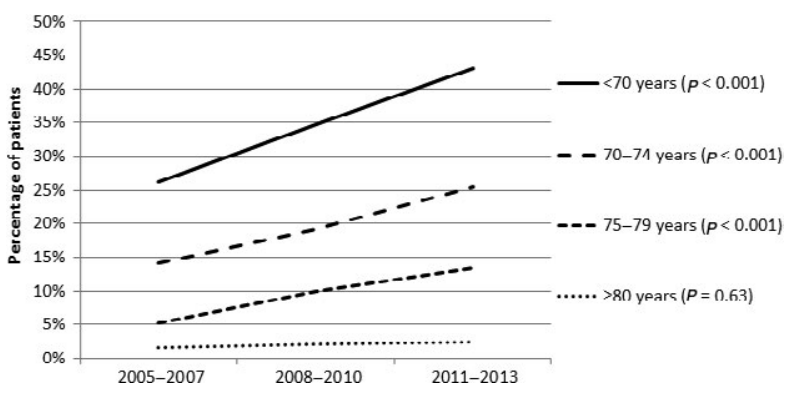

Figure 1. Administration of chemotherapy to patients diagnosed with metastatic pancreatic cancer in consecutive time periods in the Netherlands, by age group.

Median overall survival (OS) of patients with metastatic pancreatic cancer was 9.5 weeks (with rising age of patients $[<70,70-74,75-79, \geq 80$ years $]: 13-10-8-5$ weeks, respectively, $P<0.001$ ), and OS was 7 weeks in untreated patients versus 25 weeks (5.7 months) in patients who received chemotherapy $(P<0.001)$. As many as $26 \%$ of all patients died within 30 days after diagnosis (with rising age: $19-26-32-43 \%, P<0.001$ ). In patients who survived 30 days, Chemotherapy-treated patients under 75 years survived longer compared to untreated patients (conditional survival $[\mathrm{CS}]<70$ years: median 26 vs. 12 weeks, $70-74$ years: 27 vs. 11 weeks, both $P<0.001$ ), but the survival difference was smaller in patients over 75 years of age (75-79 years: median 20 vs. 11 weeks, $P<0.001, \geq 80$ years: 16 vs. 10 weeks, $P=0.02$, Fig. 2).

\section{Patients receiving systemic chemotherapy}

Median age of 2,180 patients who received palliative chemotherapy for metastatic pancreatic cancer was 63 years (range, 21-86 years) and increased from 62 years in 2005-2007 to 64 years in 2011-2013. Eight per cent of treated patients were 75 years or older and only few patients were over 80 years of age $(n=35,1.6 \%)$. With rising age $(<70,70-74,75-79, \geq 80$ years), the prevalence of a prior cancer diagnosis and the number of comorbid conditions increased (both $P<0.001$ ), particularly cardiac and vascular diseases $(P<0.001$ and $P=0.001$, respectively, Table 2). Furthermore, older patients less often had microscopic verification of the current cancer $(91 \%$, $88 \%, 87 \%, 77 \%$, respectively, $P=0.009$ ), although they all received chemotherapy.

The date of initiation of chemotherapy was available in $77 \%$ of patients and characteristics of these patients did not differ from the total group of patients (data not shown). Median time-to-chemotherapy was 25 days ([p25p75] 15-43 days) and elderly patients started chemotherapy sooner after diagnosis (Table 2), as well as patients with nonhead tumors (head: median 32 days, nonhead: 21, 
Table 1. Characteristics of patients with primary pancreatic adenocarcinoma and synchronous distant metastases in the period 2005-2013 in the Netherlands, by administration of chemotherapy (CT) and logistic regression analyses predicting administration of chemotherapy.

\begin{tabular}{|c|c|c|c|c|c|c|}
\hline & \multirow{2}{*}{$\begin{array}{l}\text { Patients } \\
N=9407(\%)\end{array}$} & \multirow{2}{*}{$\begin{array}{l}C T \\
\%\end{array}$} & \multicolumn{2}{|c|}{ Univariable analysis } & \multicolumn{2}{|c|}{ Multivariable analysis } \\
\hline & & & OR $(95 \% \mathrm{Cl})$ & $P$-value & OR $(95 \% \mathrm{Cl})$ & $P$-value \\
\hline Age & & & & $<0.001$ & & $<0.001$ \\
\hline$<70$ years & $4729(50)$ & 35 & 1.00 & & 1.00 & \\
\hline 70-74 years & $1623(17)$ & 20 & $0.46(0.41-0.53)$ & & $0.49(0.43-0.57)$ & \\
\hline $75-79$ years & $1437(15)$ & 9.9 & $0.20(0.17-0.24)$ & & $0.23(0.19-0.28)$ & \\
\hline$\geq 80$ years & $1618(17)$ & 2.2 & $0.04(0.03-0.06)$ & & $0.06(0.04-0.09)$ & \\
\hline Year of diagnosis & $9407(100)$ & 23 & $1.12(1.10-1.15)$ & $<0.001$ & $1.12(1.10-1.15)$ & $<0.001$ \\
\hline \multicolumn{7}{|l|}{ Gender } \\
\hline Male & $4852(52)$ & 25 & 1.00 & 0.001 & & \\
\hline Female & $4555(48)$ & 22 & $0.85(0.77-0.93)$ & & & \\
\hline \multicolumn{7}{|l|}{ History of cancer } \\
\hline No & $8104(86)$ & 24 & 1.00 & $<0.001$ & 1.00 & 0.07 \\
\hline Yes & $1303(14)$ & 18 & $0.70(0.60-0.81)$ & & $0.86(0.73-1.01)$ & \\
\hline \multicolumn{7}{|l|}{ SES } \\
\hline High & $2,839(30)$ & 26 & 1.00 & $<0.001$ & 1.00 & 0.006 \\
\hline Intermediate & $3,736(40)$ & 23 & $0.89(0.80-1.00)$ & & $0.95(0.84-1.07)$ & \\
\hline Low & $2,832(30)$ & 21 & $0.76(0.67-0.86)$ & & $0.81(0.71-0.93)$ & \\
\hline Tumor verification & & & & $<0.001$ & & $<0.001$ \\
\hline Verified & $6,486(69)$ & 30 & 1.00 & & 1.00 & \\
\hline No verification & $2,921(31)$ & 7 & $0.18(0.15-0.21)$ & & $0.29(0.25-0.34)$ & \\
\hline Primary tumor & & & & $<0.001$ & & \\
\hline $\begin{array}{l}\text { Head of } \\
\text { pancreas }\end{array}$ & 4567 (49) & 21 & 1.00 & & 1.00 & \\
\hline Body or tail & 3254 (35) & 27 & $1.42(1.28-1.57)$ & & $1.33(1.19-1.49)$ & $<0.001$ \\
\hline Overlapping/NOS & $1586(17)$ & 20 & $0.95(0.83-1.10)$ & & $0.98(0.84-1.14)$ & \\
\hline \multicolumn{7}{|l|}{ Metastatic site } \\
\hline 1 & $6283(67)$ & 24 & 1.00 & $<0.001$ & 1.00 & $<0.001$ \\
\hline$\geq 2$ & $2808(30)$ & 23 & $0.95(0.86-1.06)$ & & $0.79(0.70-0.89)$ & \\
\hline Unknown & $316(3.4)$ & 12 & $0.44(0.31-0.62)$ & & $0.62(0.43-0.90)$ & \\
\hline \multicolumn{7}{|l|}{ Sensitivity analysis ${ }^{1}$} \\
\hline Comorbid c. & $(n=1697)$ & & & $<0.001$ & 2 & 0.06 \\
\hline 0 & $420(25)$ & 36 & 1.00 & & 1.00 & \\
\hline 1 & $466(27)$ & 26 & $0.63(0.47-0.83)$ & & $0.78(0.57-1.07)$ & \\
\hline$\geq 2$ & $590(35)$ & 19 & $0.40(0.30-0.54)$ & & $0.67(0.48-0.94)$ & \\
\hline Unknown & $221(13)$ & 16 & $0.34(0.23-0.52)$ & & - & \\
\hline Comorbid c. & (\% yes) & & (yes vs. no) & & 2 & \\
\hline Diabetes & $394(27)$ & 23 & $0.82(0.63-1.08)$ & 0.16 & & \\
\hline Cardiac & $353(24)$ & 15 & $0.43(0.32-0.60)$ & $<0.001$ & & \\
\hline Vascular & $271(18)$ & 17 & $0.51(0.36-0.72)$ & $<0.001$ & $0.69(0.47-1.04)$ & 0.07 \\
\hline Pulmonary & $170(12)$ & 18 & $0.58(0.38-0.87)$ & 0.009 & & \\
\hline Hypertension & $450(31)$ & 23 & $0.79(0.61-1.02)$ & 0.07 & & \\
\hline Digestive tract & $151(10)$ & 28 & $1.11(0.76-1.61)$ & 0.60 & & \\
\hline
\end{tabular}

CT, chemotherapy; Comorbid c., Comorbid conditions; SES, socioeconomic status; NOS, not otherwise specified; OR, odds ratio; Cl, Confidence Interval.

${ }^{1}$ Region-wide data only $n=1697$ (18\% of all patients). Multivariable model adjusted for variables included in model using nationwide data (age, year of diagnosis, history of cancer, SES, tumor verification, primary tumor and number of metastatic sites).

${ }^{2}$ Excluding $n=221$ patients with unknown comorbid conditions because of collinearity.

$P<0.001)$ and patients with at least two metastatic sites (1: median 27 days, $\geq 2$ : 22, $P<0.001$ ).

With rising age $(<70,70-74,75-79, \geq 80$ years $)$, median OS of treated patients decreased: 25, 26, 19, and 16 weeks, respectively, $(P=0.003)$. In univariable survival analysis of patients who received chemotherapy, a higher probability of worse OS was found in patients over 75 years of age, patients treated in earlier years of our study period, without microscopic tumor verification, with nonhead cancer, and in patients with multiple metastatic sites (Table 3). In the multivariable Cox proportional hazard model, all these characteristics were independently associated with a poor OS. Compared with chemotherapy-treated patients younger than 70 years of age, patients over 75 years of 


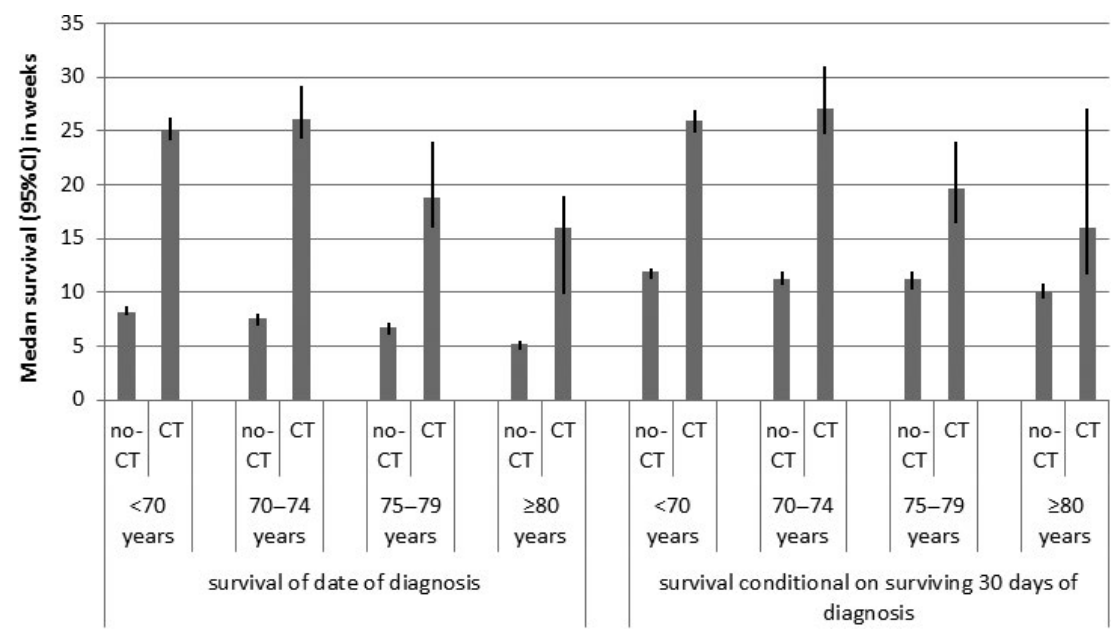

Figure 2. Median overall survival and conditional overall survival with $95 \%$ confidence interval of patients who received palliative chemotherapy (CT) for metastatic pancreatic cancer compared with untreated patients (no-CT), by age group.

age who received chemotherapy showed a worse OS (Hazard Ratio [HR] $(75-79$ vs. $<70)=1.21,95 \%$ CI $1.02-1.44$; HR $(\geq 80$ vs. $<70)=1.48,95 \%$ CI: $1.06-2.07)$, but the intermediate age group did not (HR $[70-74$ vs. $<70]=0.92$, $95 \%$ CI: $0.81-1.03, P=0.16$ ). In sensitivity analysis, the number and type of comorbid conditions of treated patients seemed not significantly associated with a poor OS (borderline: pulmonary diseases: adjusted $\mathrm{HR}=1.38,95 \%$ CI: $0.94-2.01, P=0.10$ ).

Using survival time calculated from the starting date of chemotherapy, median OS of treated patients was 20 weeks. With rising age $(<70,70-74,75-79, \geq 80$ years $)$, median survival was $20,22,16$ and 13 weeks, respectively, $(P=0.006$, Fig. 3). No survival difference was found according to tumor location (univariable HR [body/tail vs head] $=1.07$, 95\% CI: $0.96-1.19, P=0.43$ ), but other above-mentioned prognostic characteristics were independently associated with a worse OS (age: HR $[70-74$ vs $<70]=0.93,95 \%$ CI: $0.81-1.07$, HR $[75-79$ vs $<70]=1.24,95 \%$ CI: $1.02-1.51$, HR $[\geq 80$ vs. $<70]=1.68,95 \%$ CI $1.13-2.50$ ).

\section{Discussion}

To our knowledge, this is the first nationwide study of patients with metastatic pancreatic cancer that investigated chemotherapy use and survival in multiple elderly age groups. The administration of palliative systemic therapy doubled between 2005 and 2013 in all age groups. Compared with younger patients receiving chemotherapy, treated patients over 75 years of age less often underwent microscopic tumor verification of cancer and showed a worse overall survival.

In consistent with previous population-based reports, overall survival of patients with primary metastatic pancreatic cancer in our study was only $2-3$ months [4, $5,18]$. Our nationwide study also confirmed a recent regional report from the Netherlands that the administration of palliative chemotherapy has increased rapidly in the past decade [3]. Chemotherapy prescription in the Netherlands, however, (overall 23\%, patients surviving 30 days $31 \%$ ), seemed relatively low compared with population-based studies from the USA and France (42$54 \%)[10,19-21]$. Although no information on the type of chemotherapy was available in our study, it is plausible that gemcitabine-based therapies were prescribed to the vast majority of patients in the selected time period [20-22]. Treatment preference for gemcitabine was mainly based on its favorable clinical benefit response (pain, performance status, weight) and toxicity profile compared to 5 -fluorouracil $(5-\mathrm{FU})[23,24]$. Only recently, the studies by Conroy et al. on FOLFIRINOX (oxaliplatin, irinotecan, fluorouracil, and leucovorin) [8] and Von Hoff et al. on the combination of gemcitabine and nab-paclitaxel (MPACT-trial) [9] opened new treatment perspectives [25-27]. However, despite a good performance status of included patients, prolonged survival in these studies went along with an increased risk of side effects. Possibly, modified FOLFIRINOX or gemcitabine with nab-paclitaxel treatment may be beneficial to older patients or patients with a less favourable performance status [28].

Similar to other reports $[3,20,21]$, chemotherapy use in the current study was far less likely in elderly patients with metastatic pancreatic cancer. Although the number of octogenarians receiving chemotherapy hardly increased, in the course of our study the age of patients who received palliative chemotherapy rose. In patients aged 70-74 years who received chemotherapy, tumor verification rate, timing of chemotherapy, early mortality and overall survival 
Table 2. Characteristics of patients who received palliative chemotherapy (CT) for metastatic pancreatic cancer in the period 2005-2013 in the Netherlands, by age group.

\begin{tabular}{|c|c|c|c|c|c|c|}
\hline & $\begin{array}{l}\text { All patients } \\
N=2180 \%\end{array}$ & $\begin{array}{l}<70 \text { years } \\
N=1674 \%\end{array}$ & $\begin{array}{l}70-74 \text { years } \\
N=329 \%\end{array}$ & $\begin{array}{l}75-79 \text { years } \\
N=142 \%\end{array}$ & $\begin{array}{l}\geq 80 \text { years } \\
N=35 \%\end{array}$ & $\begin{array}{l}\mathrm{Chi}^{2} \\
P \text {-value }\end{array}$ \\
\hline \multicolumn{7}{|l|}{ Patient } \\
\hline \multicolumn{7}{|l|}{ Gender } \\
\hline Male & $1194(55)$ & 56 & 51 & 54 & 57 & \multirow[t]{2}{*}{0.49} \\
\hline Female & $986(45)$ & 44 & 49 & 46 & 43 & \\
\hline \multicolumn{7}{|c|}{ Socioeconomic status (SES) } \\
\hline High & $724(33)$ & 33 & 34 & 29 & 40 & \multirow{3}{*}{0.56} \\
\hline Intermediate & $874(40)$ & 40 & 38 & 42 & 46 & \\
\hline Low & $582(27)$ & 27 & 28 & 29 & 14 & \\
\hline \multicolumn{7}{|l|}{ History of cancer } \\
\hline No & $1944(89)$ & 91 & 85 & 77 & 77 & \multirow[t]{2}{*}{$<0.001$} \\
\hline Yes & $236(11)$ & 8.7 & 15 & 23 & 23 & \\
\hline Comorbid c. ${ }^{1}$ & $(n=420)$ & $(n=325)$ & $(n=64)$ & $(n=27)$ & $(n=4)$ & \multirow[t]{6}{*}{$<0.001$} \\
\hline 0 & $152(36)$ & 42 & 17 & 22 & 0 & \\
\hline 1 & $122(29)$ & 30 & 25 & 26 & 50 & \\
\hline $2+$ & $110(26)$ & 20 & 52 & 37 & 25 & \\
\hline Unknown & $36(8.6)$ & 8.3 & 6.3 & 15 & 25 & \\
\hline $\begin{array}{l}\text { Comorbid c. } \\
\text { (\%yes) }{ }^{1}\end{array}$ & $(n=384)^{2}$ & $(n=298)^{2}$ & $(n=60)^{2}$ & $(n=23)^{2}$ & $(n=3)^{2}$ & \\
\hline Diabetes & $92(24)$ & 21 & 35 & 30 & 0 & 0.09 \\
\hline Cardiac disease & $54(14)$ & 9.7 & 28 & 26 & 67 & $<0.001$ \\
\hline Vascular disease & $45(12)$ & 8.4 & 25 & 17 & 33 & 0.001 \\
\hline Pulmonary disease & $30(7.8)$ & 7.1 & 13 & 4.4 & 0 & 0.33 \\
\hline Hypertension & $103(27)$ & 24 & 40 & 26 & 33 & 0.09 \\
\hline $\begin{array}{l}\text { Digestive tract } \\
\text { disease }\end{array}$ & $42(11)$ & 9.7 & 10 & 26 & 33 & 0.06 \\
\hline \multicolumn{7}{|l|}{ Tumor } \\
\hline \multicolumn{6}{|l|}{ Tumor verification } & \multirow[t]{3}{*}{0.009} \\
\hline Verified & $1968(90)$ & 91 & 88 & 87 & 77 & \\
\hline No verification & $212(9.7)$ & 8.8 & 12 & 13 & 23 & \\
\hline \multicolumn{6}{|l|}{ Primary tumor } & \multirow[t]{4}{*}{0.27} \\
\hline Head of pancreas & $964(44)$ & 44 & 48 & 44 & 34 & \\
\hline Body or tail & $894(41)$ & 42 & 36 & 39 & 57 & \\
\hline $\begin{array}{l}\text { Other or } \\
\text { overlapping }\end{array}$ & $322(15)$ & 15 & 16 & 17 & 8.6 & \\
\hline \multicolumn{7}{|c|}{ Number of metastatic sites } \\
\hline 1 & $1497(69)$ & 69 & 69 & 63 & 69 & \multirow[t]{3}{*}{0.51} \\
\hline$\geq 2$ & $645(30)$ & 29 & 28 & 37 & 31 & \\
\hline Unknown & $38(1.7)$ & 1.8 & 2.1 & 0.7 & 0 & \\
\hline \multicolumn{7}{|l|}{ Time interval to $\mathrm{CT}$} \\
\hline $\begin{array}{l}\text { Median } \\
\text { [p25-p75] in } \\
\text { days }^{3}\end{array}$ & 25 [15-42] & 26 [15-43] & 26 [16-48] & 21 [13-33] & $18[13-34]$ & 0.007 \\
\hline$\geq 6$ weeks $^{3}$ & $443(26)$ & 27 & 29 & 17 & 12 & 0.03 \\
\hline \multicolumn{7}{|c|}{ Mortality of starting CT } \\
\hline 30-day mortality ${ }^{3}$ & $141(8.4)$ & 8.0 & 8.5 & 10.0 & 20.0 & 0.17 \\
\hline 90-day mortality ${ }^{3}$ & $541(32)$ & 31 & 31 & 44 & 48 & 0.02 \\
\hline
\end{tabular}

Comorbid c., Comorbid conditions; SES, socioeconomic status; NOS, not otherwise specified; N, number of patients.

${ }^{1}$ Region-wide data only $n=420$ ( $18 \%$ of all patients).

${ }^{2}$ excluding patients with unknown comorbid conditions.

3 If date of initiating chemotherapy is available $n=1676$ (77\% of all patients).

in our study were very similar to that of treated patients younger than 70 years. However, although very few and therefore highly selected elderly patients over 75 years of age were treated with palliative chemotherapy, a poor survival after chemotherapy was particularly found in this elderly age groups. Survival of treated elderly patients in 
Table 3. Crude median overall survival and univariable and multivariable Cox proportional hazards regression analyses predicting survival of patients who received palliative chemotherapy for metastatic pancreatic cancer in the period 2005-2013 in the Netherlands.

\begin{tabular}{|c|c|c|c|c|c|}
\hline \multirow[b]{2}{*}{ Characteristics } & \multirow[b]{2}{*}{ MS months } & \multicolumn{2}{|c|}{ Univariable analysis } & \multicolumn{2}{|c|}{ Multivarivable analysis } \\
\hline & & $\operatorname{HR}(95 \% \mathrm{Cl})$ & $P$-value & $\mathrm{HR}(95 \% \mathrm{CI})$ & $P$-value \\
\hline Age & & & 0.003 & & 0.008 \\
\hline$<70$ years & 5.8 & Ref & & Ref & \\
\hline 70-74 years & 6.0 & $0.93(0.83-1.05)$ & & $0.92(0.81-1.03)$ & \\
\hline $75-79$ years & 4.3 & $1.25(1.05-1.48)$ & & $1.21(1.02-1.44)$ & \\
\hline$\geq 80$ years & 3.7 & $1.58(1.13-2.21)$ & & $1.48(1.06-2.07)$ & \\
\hline Year of diagnosis & 5.7 & $0.98(0.96-1.00)$ & 0.05 & $0.98(0.96-1.00)$ & 0.03 \\
\hline Gender & & & 0.30 & & \\
\hline Male & 5.5 & Ref & & & \\
\hline Female & 6.2 & $0.96(0.88-1.04)$ & & & \\
\hline History of cancer & & & 0.85 & & \\
\hline No & 5.7 & Ref & & & \\
\hline Yes & 6.0 & $0.99(0.86-1.13)$ & & & \\
\hline \multicolumn{6}{|l|}{ SES } \\
\hline High & 5.8 & Ref & 0.27 & & \\
\hline Medium & 5.5 & $1.05(0.95-1.16)$ & & & \\
\hline Low & 6.0 & $1.09(0.98-1.22)$ & & & \\
\hline Tumor verification & & & 0.02 & & 0.007 \\
\hline Verification & 5.8 & Ref & & Ref & \\
\hline No verification & 4.9 & $1.19(1.03-1.37)$ & & $1.22(1.05-1.41)$ & \\
\hline Primary tumor & & & $<0.001$ & & 0.002 \\
\hline Head & 6.2 & Ref & & Ref & \\
\hline Body or tail & 5.4 & $1.21(1.11-1.33)$ & & $1.17(1.07-1.29)$ & \\
\hline Overlapping/NOS & 5.7 & $1.17(1.03-1.33)$ & & $1.17(1.03-1.33)$ & \\
\hline Metastatic sites & & & $<0.001$ & & $<0.001$ \\
\hline 1 & 6.2 & Ref & & Ref & \\
\hline$\geq 2$ & 5.0 & $1.38(1.25-1.51)$ & & $1.36(1.23-1.49)$ & \\
\hline Unknown & 5.6 & $1.13(0.82-1.56)$ & & $1.07(0.76-1.49)$ & \\
\hline \multicolumn{6}{|l|}{ Sensitivity analysis ${ }^{1}$} \\
\hline Comorbid c. & & & 0.06 & 2 & \\
\hline 0 & 5.8 & Ref & & & \\
\hline 1 & 6.0 & $0.97(0.76-1.23)$ & & & \\
\hline$\geq 2$ & 5.4 & $1.18(0.96-1.51)$ & & & \\
\hline Unknown & 6.3 & $0.71(0.49-1.03)$ & & & \\
\hline Comorbid c. & (if yes) & (yes vs. no) & & 2 & \\
\hline Diabetes & 5.8 & $1.10(0.87-1.40)$ & 0.42 & & \\
\hline Cardiac & 5.2 & $0.97(0.72-1.30)$ & 0.84 & & \\
\hline Vascular & 4.8 & $1.02(0.74-1.40)$ & 0.90 & & \\
\hline Pulmonary & 5.4 & $1.40(0.96-2.03)$ & 0.10 & $1.38(0.94-2.01)$ & 0.10 \\
\hline Hypertension & 5.8 & $1.16(0.92-1.46)$ & 0.22 & & \\
\hline Digestive tract & 7.1 & $0.84(0.61-1.16)$ & 0.29 & & \\
\hline
\end{tabular}

Survival calculated from date of diagnosis (100\% of patients).

MS, median survival; Comorbid C., Comorbid conditions; SES, socioeconomic status; NOS, not otherwise specified; HR, hazard ratio; Cl, Confidence Interval.

${ }^{1}$ Region-wide data only $n=420$ (18\% of all patients). Multivariable model adjusted for variables included in model using nationwide data (age, year of diagnosis, tumor verification, primary tumor, and number of metastatic sites).

${ }^{2}$ Excluding $n=36$ patients with unknown comorbid conditions because of collinearity.

our nationwide study ( $\geq 75$ years: median 4.0 months) was strikingly worse than the median of 7-8 months in previous mono-institutional cohorts of patients over 75 years of age $[11,12]$. Our observations are likely related to the nationwide character of our study with a less selective cohort of elderly patients. Furthermore, additional analyses of the MPACT-study data showed that older age (defined as $\geq 65$ years) was an independent predictor for both worse overall and progression-free survival [29]. Unlike older age, in our study comorbid conditions seemed not strongly associated with a worse overall survival of treated patients. Possibly, a loss of 'functional reserve' due to the process of aging may add to a worse survival of elderly patients, resulting in increased toxicity or reduced 


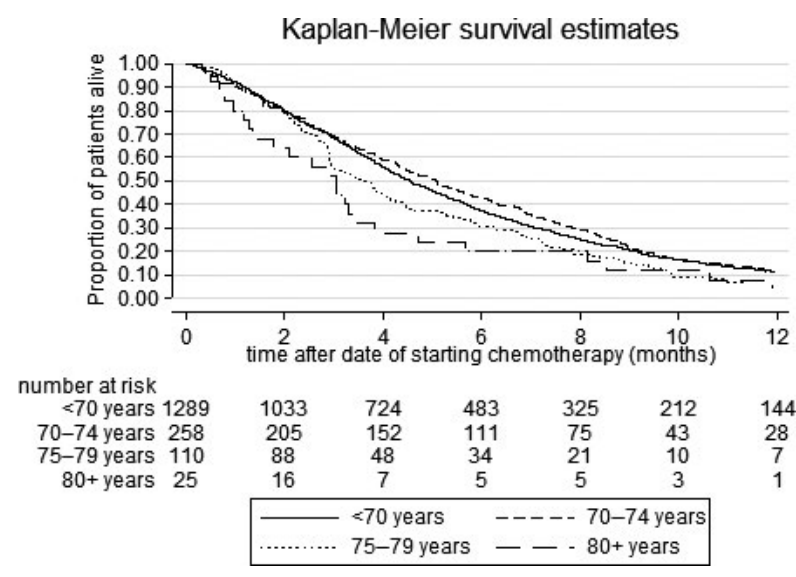

Figure 3. Crude overall survival of patients who received palliative chemotherapy for metastatic pancreatic cancer, by age group. Survival calculated from date of starting chemotherapy ( $77 \%$ of patients). Log rank test $P=0.006$.

dose adherence and consequently reduced treatment efficacy and survival. Therefore, geriatric characteristics and co-morbid features predictive of treatment intolerance should be better defined.

Overall, survival of the total group of patients who received palliative chemotherapy in our study was similar to other observational studies (median 5.7 vs. 5-6.4 months) $[13,20,22]$. Although as many as $32 \%$ of patients in our study died within 90 days of starting chemotherapy, this may reflect the treatment goal directed at symptom management and the progressive character of pancreatic cancer. Generally, chemotherapy use in the last weeks of life is considered undesirable end-of-life care [30]. Particularly in pancreatic cancer patients with their already poor prognosis, palliative chemotherapy may jeopardize quality of end-of-life care and yield a limited costeffectiveness [31]. Therefore, a better selection of patients with pancreatic cancer who may benefit from available palliative chemotherapies is clearly needed.

Most previous observational studies only included patients with microscopically confirmed pancreatic cancer $[5,11,13,21,22,32]$. Although pathologic confirmation of pancreatic cancer prior to chemotherapy is strongly recommended [27, 33], one in ten of treated patients in our study started chemotherapy without prior microscopic tumor verification. Especially in elderly patients, microscopic verification was often omitted. Although in selected patients, a suspected mass on computer tomography (CT), elevated serum marker CA19-9 and cancer-specific symptoms may result in a high specificity for pancreatic cancer [34], misdiagnosis cannot be ruled out [35, 36].

Our population-based study also revealed that especially patients with pancreatic head tumors started palliative chemotherapy several weeks after diagnosis (median,
4-5 weeks). Many patients with pancreatic head tumors undergo stent placement to solve bile duct obstruction [37]. Other patients must recover from explorative surgical procedures [38-40]. Stent dysfunction and surgical morbidity may have delayed or precluded chemotherapy in a number of patients with metastatic disease. Indeed, patients with pancreatic head cancer in our study less likely received palliative chemotherapy $(21 \%$, vs. $27 \%$ in patients with body or tail disease).

Important limitations in this population-based study concern the availability of data. Firstly, completeness of pancreatic cancer diagnoses in the NCR was questioned recently [41]. Although chemotherapy use in elderly patients and survival of untreated patients might slightly be overestimated, analyses of treated patients are expected to be highly accurate. Secondly, the NCR does not contain nationwide data on comorbid conditions and performance status of patients. However, patients who received palliative chemotherapy for pancreatic cancer may already have a relatively favorable performance status and available (region-wide) comorbidity data did not show significant associations with a poor survival. Furthermore, this nationwide populationwide study reflects real-world treatment and survival patterns and also included patients without microscopic confirmation of cancer and patients who underwent pancreatic resection $(0.7 \%)$. Excluding these patient groups did not alter our results. Thirdly, although conditional survival analysis has reduced survivor treatment bias (immortal time bias), treatment choice was not at random (treatment selection bias) [17]. Therefore, the observed differences between treated and untreated patients are likely an overestimation of true survival differences. Finally, starting dates of chemotherapy were available in only three quarters of patients. However, patients were representative for the total patient population and the available data revealed important information about the treatment process. The recently initiated Dutch nationwide PAncreatic CAncer Project (PACAP), which combines data from the NCR with the Dutch Pancreatic Cancer Audit and Dutch Pancreatic Biobank, is expected to provide more detailed information on systemic treatment in patients with pancreatic cancer, such as type and amount of chemotherapy [42].

\section{Conclusions}

Despite a limited chemotherapy use in elderly patients, suggestive of strong selection, especially patients over 75 years of age who received chemotherapy showed a poor survival. Improved definition of the geriatric characteristics and co-morbid features predictive of treatment intolerance is necessary to optimize selection of elderly 
patients for palliative chemotherapy. In addition, appropriate chemotherapy regimens are required that are better tolerated by elderly patients.

\section{Acknowledgments}

The authors would like to thank the registration team of the Netherlands Comprehensive Cancer Organisation (IKNL) for collecting data for the NCR in all hospitals in the Netherlands.

\section{Conflict of Interest}

None declared.

\section{References}

1. Lepage, C., R. Capocaccia, M. Hackl, V. Lemmens, E. Molina, D. Pierannunzio, et al. 2015. Survival in patients with primary liver cancer, gallbladder and extrahepatic biliary tract cancer and pancreatic cancer in Europe 1999-2007: Results of EUROCARE-5. Eur. J. Cancer 51:2169-2178.

2. Netherlands Cancer Registry (NCR). Dutch Cancer Figures. http://www.cijfersoverkanker.nl

3. Bernards, N., N. Haj Mohammad, GJ. Creemers, IH. de Hingh, HW van Laarhoven, VE Lemmens. 2015. Ten weeks to live: a population-based study on treatment and survival of patients with metastatic pancreatic cancer in the south of the Netherlands. Acta Oncol. 54:403-410.

4. Baxter, N. N., B. A. Whitson, and T. M. Tuttle. 2007. Trends in the treatment and outcome of pancreatic cancer in the United States. Ann. Surg. Oncol. $14: 1320-1326$.

5. Worni, M., U. Guller, R. R. White, A. W. Castleberry, R. Pietrobon, T. Cerny, et al. 2013. Modest improvement in overall survival for patients with metastatic pancreatic cancer: a trend analysis using the surveillance, epidemiology, and end results registry from 1988 to 2008. Pancreas 42:1157-1163.

6. Coupland, V. H., H. M. Kocher, D. P. Berry, W. Allum, K. M. Linklater, J. Konfortion, et al. 2012. Incidence and survival for hepatic, pancreatic and biliary cancers in England between 1998 and 2007. Cancer Epidemiol. 36:e207-e214.

7. van der Geest, L. G., M. G. Besselink, Y. R. van Gestel, O. R. Busch, I. H. de Hingh, K. P. de Jong, et al. 2016. Pancreatic cancer surgery in elderly patients: balancing between short-term harm and long-term benefit. A population-based study in the Netherlands. Acta Oncol. 55:278-285.

8. Conroy, T., F. Desseigne, M. Ychou, O. Bouche, R. Guimbaud, Y. Becouarn, et al. 2011. FOLFIRINOX versus gemcitabine for metastatic pancreatic cancer. N. Engl. J. Med. 364:1817-1825.

9. Von Hoff, D. D., T. Ervin, F. P. Arena, E. G. Chiorean, J. Infante, M. Moore, et al. 2013. Increased survival in pancreatic cancer with nab-paclitaxel plus gemcitabine. N. Engl. J. Med. 369:1691-1703.

10. David, M., C. Lepage, J. L. Jouve, V. Jooste, M. Chauvenet, J. Faivre, et al. 2009. Management and prognosis of pancreatic cancer over a 30 -year period. Br. J. Cancer 101:215-218.

11. Li, D., M. Capanu, K. H. Yu, M. A. Lowery, D. P. Kelsen, and E. M. O'Reilly. 2015. Treatment, outcomes, and clinical trial participation in elderly patients with metastatic pancreas adenocarcinoma. Clin. Colorectal Cancer 14:269-76e1.

12. Hentic, O., C. Dreyer, V. Rebours, M. Zappa, P. Levy, E. Raymond, et al. 2011. Gemcitabine in elderly patients with advanced pancreatic cancer. World J. Gastroenterol. 17:3497-3502.

13. Chen, Y. G., H. H. Pan, M. S. Dai, C. Lin, C. S. Lu, S. L. Su, et al. 2015. Impact of comorbidity and age on determinants therapeutic strategies in advanced pancreatic head cancer patients with obstructive jaundices. Medicine 94:e1298.

14. Fritz, A., C. Percy, A. Jack, K. Shanmugaratnam, L. Sobin, D. M. Parkin, et al. 2000. International classification of diseases for oncology (ICD-O)ed., vol. 3rd Ed. World Health Organization, Geneva.

15. Sobin, L. H., M. K. Gospodarowitz, and C. Wittekind. 2009. TNM Classifications of malignant tumours seventh editioned. Wiley-Blackwell, Hoboken, NJ.

16. Louwman, W. J., M. J. Aarts, S. Houterman, F. J. van Lenthe, J. W. Coebergh, and M. L. Janssen-Heijnen. 2010. A 50\% higher prevalence of life-shortening chronic conditions among cancer patients with low socioeconomic status. Br. J. Cancer 103:1742-1748.

17. Austin, P. C., and R. W. Platt. 2010. Survivor treatment bias, treatment selection bias, and propensity scores in observational research. J. Clin. Epidemiol. 63:136-138.

18. Haj Mohammad, N., N. Bernards, M. G. Besselink, O. R. Busch, J. W. Wilmink, G. J. Creemers, et al. 2016. Volume matters in the systemic treatment of metastatic pancreatic cancer: a population-based study in the Netherlands. J. Cancer Res. Clin. Oncol. 142:1353-1360.

19. Abraham, A., W. B. Al-Refaie, H. M. Parsons, V. Dudeja, S. M. Vickers, and E. B. Habermann. 2013. Disparities in pancreas cancer care. Ann. Surg. Oncol. 20:2078-2087.

20. Enewold, L., L. C. Harlan, T. Tucker, and S. McKenzie. 2015. Pancreatic cancer in the USA: persistence of undertreatment and poor outcome. J. Gastrointest. Cancer 46:9-20.

21. Oberstein, P. E., D. L. Hershman, L. G. Khanna, J. A. Chabot, B. J. Insel, and A. I. Neugut. 2013. Uptake and 
patterns of use of gemcitabine for metastatic pancreatic cancer: a population-based study. Cancer Invest. 31:316-322.

22. Kim, H. W., J. C. Lee, K. H. Paik, Y. S. Lee, J. H. Hwang, and J. Kim. 2015. Initial metastatic site as a prognostic factor in patients with stage iv pancreatic ductal adenocarcinoma. Medicine 94:e1012.

23. Burris, H. A. III, M. J. Moore, J. Andersen, M. R. Green, M. L. Rothenberg, M. R. Modiano, et al. 1997. Improvements in survival and clinical benefit with gemcitabine as first-line therapy for patients with advanced pancreas cancer: a randomized trial. J. Clin. Oncol. 15:2403-2413.

24. Sultana, A., C. T. Smith, D. Cunningham, N. Starling, J. P. Neoptolemos, and P. Ghaneh. 2007. Meta-analyses of chemotherapy for locally advanced and metastatic pancreatic cancer. J. Clin. Oncol. 25:2607-2615.

25. Oettle, H. 2014. Progress in the knowledge and treatment of advanced pancreatic cancer: from benchside to bedside. Cancer Treat. Rev. 40:1039-1047.

26. Hidalgo, M., S. Cascinu, J. Kleeff, R. Labianca, J. M. Lohr, J. Neoptolemos, et al. 2015. Addressing the challenges of pancreatic cancer: future directions for improving outcomes. Pancreatology 15:8-18.

27. National Comprehensive Cancer Network (NCCN). Clinical Practice Guidelines in Oncology, Pancreatic Adenocarcinoma (version 2-2014).

28. Stein, S. M., E. S. James, Y. Deng, X. Cong, J. S. Kortmansky, J. Li, et al. 2016. Final analysis of a phase II study of modified FOLFIRINOX in locally advanced and metastatic pancreatic cancer. Br. J. Cancer 114:809-812.

29. Tabernero, J., E. G. Chiorean, J. R. Infante, S. R. Hingorani, V. Ganju, C. Weekes, et al. 2015. Prognostic factors of survival in a randomized phase III trial (MPACT) of weekly nab-paclitaxel plus gemcitabine versus gemcitabine alone in patients with metastatic pancreatic cancer. Oncologist 20:143-150.

30. Earle, C. C., M. B. Landrum, J. M. Souza, B. A. Neville, J. C. Weeks, and J. Z. Ayanian. 2008. Aggressiveness of cancer care near the end of life: is it a quality-of-care issue? J. Clin. Oncol. 26:3860-3866.

31. Cherny, N. I., R. Sullivan, U. Dafni, J. M. Kerst, A. Sobrero, C. Zielinski, et al. 2015. A standardised, generic, validated approach to stratify the magnitude of clinical benefit that can be anticipated from anti-cancer therapies: the European Society for Medical Oncology
Magnitude of Clinical Benefit Scale (ESMO-MCBS). Ann. Oncol. 26:1547-1573.

32. Choi, Y., T. Y. Kim, K. H. Lee, S. W. Han, D. Y. Oh, S. A. Im, et al. 2014. The impact of body mass index dynamics on survival of patients with advanced pancreatic cancer receiving chemotherapy. J. Pain Symptom Manage. 48:13-25.

33. Netherlands Comprehensive Cancer Organisation (IKNL). (2011). National evidence-based guideline for pancreatic carcinoma.

34. Bernards, N., G. J. Creemers, C. J. Huysentruyt, I. H. de Hingh, G. P. van der Schelling, A. P. de Bruine, et al. 2015. The relevance of pathological verification in suspected pancreatic cancer. Cancer Epidemiol. 39:250-255.

35. Zijlstra, M., N. Bernards, I. H. de Hingh, A. J. van de Wouw, S. H. Goey, E. M. Jacobs, et al. 2016. Does long-term survival exist in pancreatic adenocarcinoma? Acta Oncol. 55:259-264.

36. Carpelan-Holmstrom, M., S. Nordling, E. Pukkala, R. Sankila, J. Luttges, G. Kloppel, et al. 2005. Does anyone survive pancreatic ductal adenocarcinoma? A nationwide study re-evaluating the data of the Finnish Cancer Registry. Gut 54:385-387.

37. Nakakura, E. K., and R. S. Warren. 2007. Palliative care for patients with advanced pancreatic and biliary cancers. Surg. Oncol. 16:293-297.

38. Bartlett, E. K., H. Wachtel, D. L. Fraker, C. M. Vollmer, J. A. Drebin, R. R. Kelz, et al. 2014. Surgical palliation for pancreatic malignancy: practice patterns and predictors of morbidity and mortality. J. Gastrointest. Surg. 18:1292-1298.

39. Spanheimer, P. M., A. R. Cyr, J. Liao, F. C. Johlin, H. Hoshi, J. R. Howe, et al. 2014. Complications and survival associated with operative procedures in patients with unresectable pancreatic head adenocarcinoma. J. Surg. Oncol. 109:697-701.

40. Insulander, J., S. Sanjeevi, M. Haghighi, T. Ivanics, A. Analatos, L. Lundell, et al. 2016. Prognosis following surgical bypass compared with laparotomy alone in unresectable pancreatic adenocarcinoma. Br. J. Surg. 103:1200-1208.

41. Fest, J., R. Ruiter, F. J. van Rooij, L. G. van der Geest, V. E. Lemmens, M. A. Ikram, et al. 2016.

Underestimation of pancreatic cancer in the national cancer registry - reconsidering the incidence and survival rates. Eur. J. Cancer 72:186-191.

42. PAncreatic CAncer Project (PACAP) https://pacap.nl/. 